Bernardo Bomfim Pinheiro

Santiago Arias Lievano

\title{
O planejamento 5D dentro da construção civil brasileira
}

Trabalho apresentado como requisito parcial à conclusão do curso de Engenharia Civil na Pontifícia Universidade Católica do Rio de Janeiro, Rio de Janeiro, Brasil.

Orientador: Carlos Eden Sardenberg Mesquita.

Rio de Janeiro Dezembro de 2021 


\section{Agradecimentos}

Primeiramente, gostaríamos de dedicar essa dissertação às nossas famílias, que nos apoiaram, incentivaram e contribuíram para a nossa graduação e experiências vividas dentro desta renomada universidade.

Gostaríamos, também de agradecer todos os amigos que nos ajudaram e participaram desta jornada, deixando essa experiência ainda mais rica.

Por fim, um agradecimento especial, ao nosso orientador Carlos Eden Sardenberg Mesquita, que além de auxiliar no desenvolvimento da dissertação, compartilhou, também, seu conhecimento e experiências acerca da metodologia BIM.

Bernardo e Santiago 


\section{Resumo}

O planejamento é uma função vital para o andamento de um empreendimento na construção civil, e, caso bem feito, pode aumentar a produtividade da construção e até mesmo reduzir o custo final do empreendimento. Por ser uma peça chave, vários métodos de aprimoração foram feitos ao mesmo. Sendo o mais atual, a metodologia Building Intelligence Modeling (BIM).

Nessa metodologia, existem as modelagens 3D, que são a modelagem da estrutura em um software $3 \mathrm{D}$, a modelagem $4 \mathrm{D}$, que é a o cronograma, e a modelagem 5D, que é o orçamento. Para cada etapa da construção, essa metodologia obtém facilidades e aprimoramentos específicos, para deixar cada fase mais precisa e próxima da realidade, além de facilitar o trabalho realizado.

No Brasil, no entanto, o uso de tal metodologia é ainda bem atrasado, tendo poucas empresas que usufruem de tal recurso. Sendo assim, é necessário, algumas vezes ir ao exterior em busca de mão de construção especializada.

Palavras-chave: Planejamento, BIM, 3D, 4D, 5D. 


\section{Abstract}

Planning is a vital function for the development of a civil construction project, and, if properly conducted, can increase the productivity of the work site and even reduce the final cost of the project. Because it is a key part, several methods of improvement have been developed for it, the most current and useful being the Building Intelligence Modeling (BIM) methodology.

In this methodology, there is $3 \mathrm{D}$ modeling, which is the modeling of the structure in a 3D software, 4D modeling, which is the time schedule, and 5D modeling, which is the Budget. For each stage of construction, this methodology obtains specific facilities and enhancements, to make each phase more accurate and closer to reality, in addition to facilitating the work performed.

In Brazil, however, the use of this methodology is still very limited, and there are few companies that take advantage of this resource. Therefore, it is sometimes necessary to go abroad in search of specialized labor.

Keywords: Planning, BIM, 3D, 4D, 5D. 


\section{SUMÁRIO}

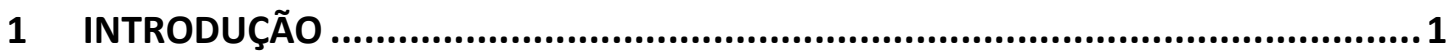

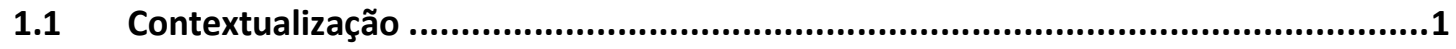

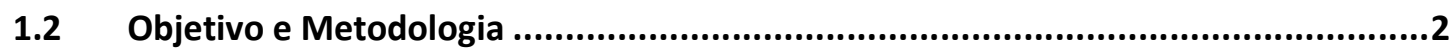

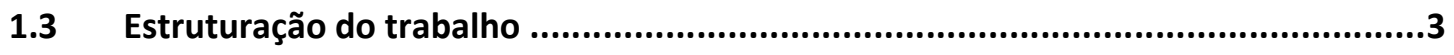

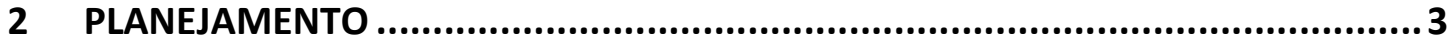

2.1 Planejamento

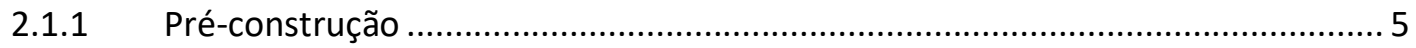

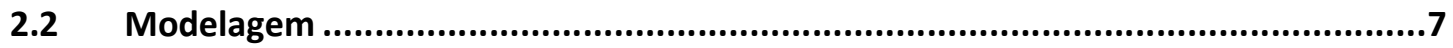

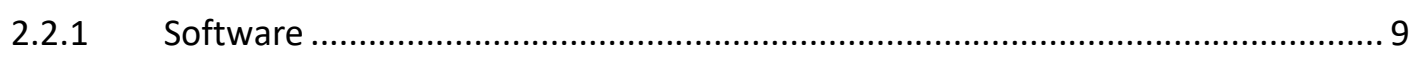

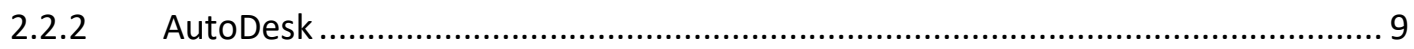

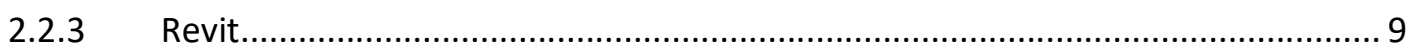

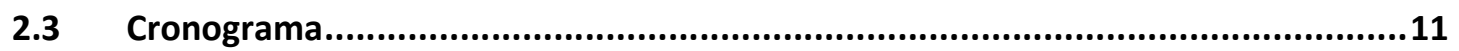

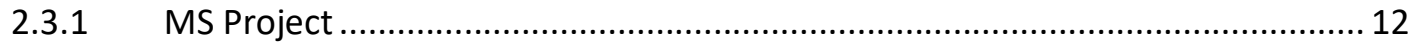

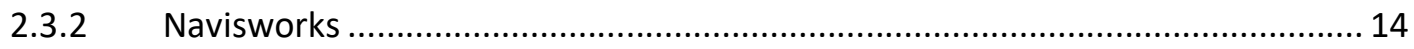

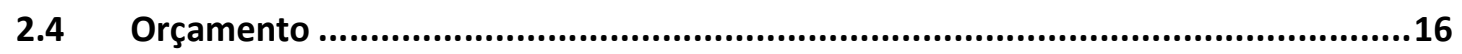

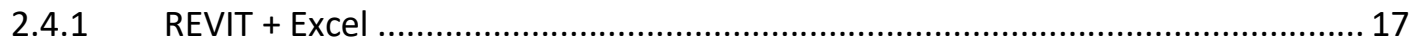

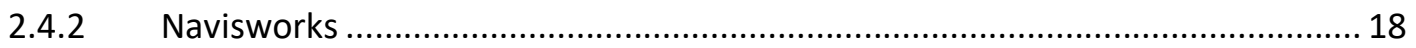

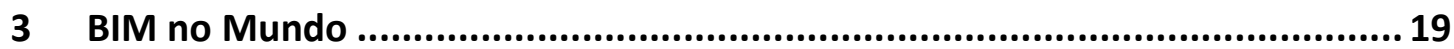

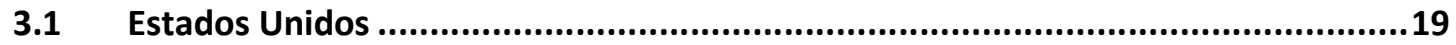

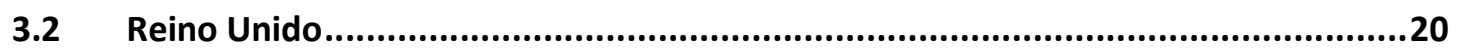

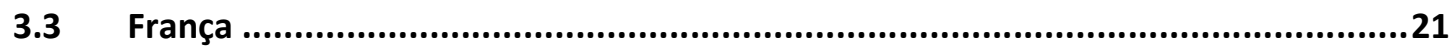

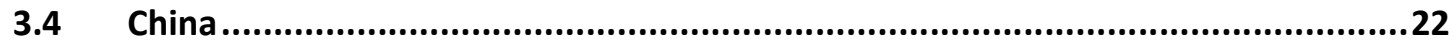

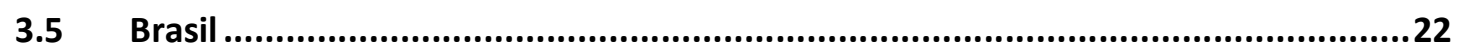

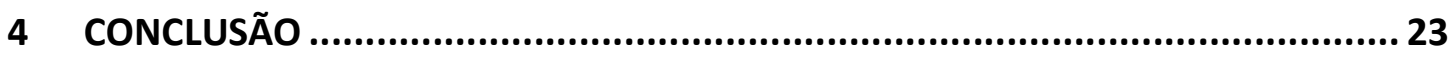

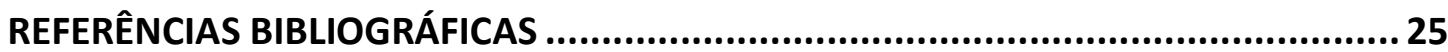




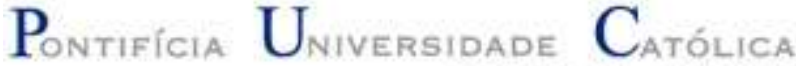

\section{ÍNDICE DE FIGURAS}

Figura 2.1.1.1 - Custos ao longo da contrução ......................................................

Figura 2.2.3.1 - Desenho de parede no Revit.......................................................... 10

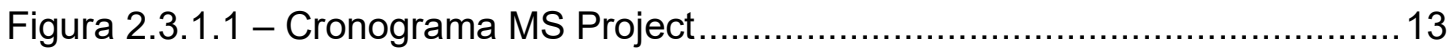

Figura 2.3.2.1 - Compatibilização Navisworks.................................................. 14

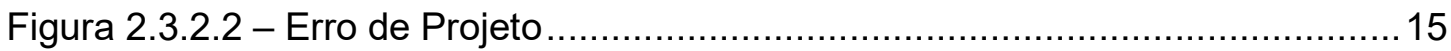

Figura 2.4.1.1 - Orçamento Revit ............................................................... 17

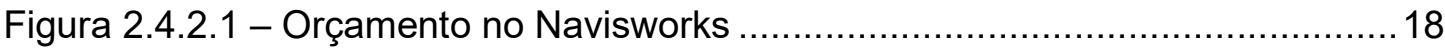

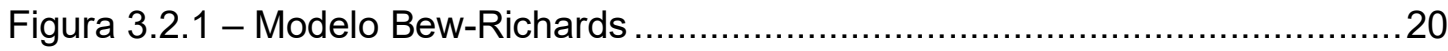

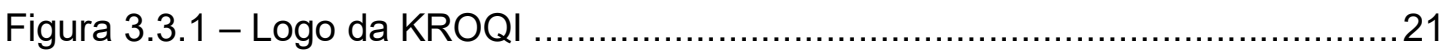




\section{INTRODUÇÃO}

\subsection{Contextualização}

O planejamento é de extrema importância para o ser humano, podendo ser aplicado em qualquer atividade realizada, desde as mais básicas, relativas à alimentação, até a organização de uma empresa, para aumentar a produtividade e faturamento.

No entanto, podendo ser apenas um optativo em algumas situações, o planejamento tem grande influência na construção civil e nas atividades imobiliárias, já que em qualquer empreendimento, tem-se um tempo hábil para construção e um limite de investimentos para realizar no empreendimento.

Em uma das primeiras grandes construções da humanidade em que se tem conhecimento e registro, as pirâmides do Egito, construídas em torno de 2580 a.C., narrase que já havia um controle de tempo para construção. O cronograma, diferentemente dos dias atuais, foi controlado através de imposições sobre o administrador da construção, uma delas sendo que caso a construção não ficasse pronta no tempo determinado, o mesmo seria aprisionado dentro da pirâmide.

Apesar da preocupação com cronograma, não se sabe se essa grande construção teve qualquer projeto avançado de engenharia, mas pode-se dizer que não havia preocupações em relação à mão de construção ou insumo. Pode-se afirmar através disso, que mesmo não havendo um controle real sobre a construção, já existia assim, um certo planejamento no sentido de cronograma.

Nos dias atuais, as construções evoluíram imensamente e para qualquer grande construção que é realizada, é imperativo a realização do planejamento das mesmas, onde 


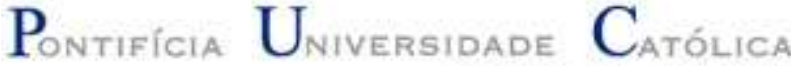 \\ DO RIO DE JANEIRO}

estão contidos o controle do tempo e controle do investimento a ser utilizado nas mesmas, com vistas aos objetivos de construção e lucratividade do empreendimento.

\subsection{Objetivo e Metodologia}

A pesquisa tem como objetivo principal apresentar as fases de um planejamento 5D dentro da metodologia Building Information Modeling (BIM).

O planejamento 5D consiste em organizar a gestão de uma construção em três grandes etapas, modelagem (3D), cronograma (4D) e orçamento (5D). Esse conceito de planejamento é praticado de diversas formas e tem evoluído bastante nos últimos anos com a ajuda de novos softwares. Junto a esse conceito e avanço tecnológico foi criada a metodologia BIM, que será, também, analisada nesse trabalho.

Esta metodologia utiliza ferramentas e tecnologias para a geração e gestão dos projetos das construções.

O BIM trabalha com modelos $3 \mathrm{D}$, dos projetos de um empreendimento, que podem ser colocados em rede, e desta, extraídos para facilitar a compatibilização entre projetos, possibilitando a tomada de decisões sobre métodos construtivos e soluções para construção. Além da representação visual tridimensional, o BIM também proporciona informações para montagem de cronogramas e oferece um forte apoio para realizar o orçamento da construção.

Atualmente a utilização do BIM para realizar um planejamento 5D é realizada em diversos países como Estados Unidos, Canadá, França, Alemanha, Reino Unido, China, entre outros. 


\subsection{Estruturação do trabalho}

Inicialmente, no capítulo 2, o estudo realizará uma análise das fases e a importância de cada etapa até o planejamento 5D, sendo as mesmas a Modelagem (3D), Cronograma (4D) e por fim a Orçamentação (5D). Além disso, será discorrido sobre os Softwares existentes e que dão suporte para cada etapa do planejamento.

Em seguida, no capítulo 3, será analisada a implementação do sistema BIM (Building Information Modelling) no Brasil, e como ele se compara ao uso do mesmo sistema em outros países.

Por fim, no Capítulo 4, será feita uma conclusão de todos os pontos levantados no estudo.

\section{PLANEJAMENTO}

\subsection{Planejamento}

O planejamento na construção civil tem início na parte de pré-construção, onde são realizados os primeiros estudos do empreendimento, para que o mesmo se torne viável financeiramente e economicamente. Essa é uma das etapas mais importantes, já que ao ser bem realizada, pode ocasionar uma redução dos gastos da construção no futuro.

A segunda parte a ser realizada no planejamento é a da modelagem dos projetos que englobam a arquitetura, estruturas, instalações, entre outras fases, onde serão feitas as análises, de compatibilização do projeto, assim como as visualizações do conjunto de 


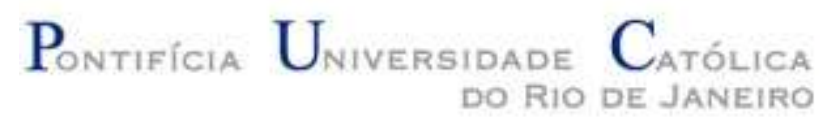

todos os estudos realizados. No modelo do Building Information Modeling, essa etapa é chamada de modelagem 3D.

A etapa seguinte, o cronograma, definirá quando e quanto tempo cada serviço da construção deverá consumir do prazo da construção. Essa previsão é importante, tanto na fase pré-construção, quanto durante, já que além de dar uma previsão de finalização da construção, pode indicar, também, como está a produtividade dos funcionários e possíveis interferências nas etapas de construção. Dentro do BIM, essa etapa chama-se modelagem 4D, em que se acrescenta o tempo em cima do modelo tridimensional.

A última etapa a ser realizada é o orçamento, onde se deve calcular todos os custos diretos e indiretos impostos sobre o empreendimento. Para esse cálculo ser o mais próximo do custo final da construção possível, é necessário que todas as fases passadas sejam feitas de forma precisa, assim, os custos de todos os materiais que serão utilizados, obtidos através da modelagem $3 \mathrm{D}$, poderão ser estimados, assim como a quantidade de mão de obra que será necessária, obtida através da modelagem 4D.

Além das 4 fases que serão abordadas nesse estudo e foram descritas acima, o modelo BIM de construção ainda aborda as modelagens $6 \mathrm{D}$ e 7D, que são a análise de sustentabilidade do edifício após a construção, e o gerenciamento do edifício após ser construído em sua fase de manutenção, respectivamente. 


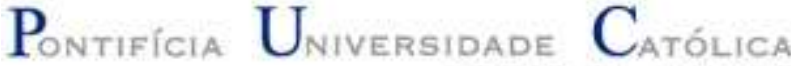 \\ DO RIO DE JANEIRO}

\subsubsection{Pré-construção}

A fase pré-construção são as atividades realizadas antes da execução da construção.

Essa fase consiste em realizar estudos de engenharia de diferentes etapas da construção, como, a estimativa de custo, o estudo de viabilidade, o planejamento, o orçamento e um projeto integrado e detalhado da construção com o intuito de garantir sua eficácia e construtibilidade.

O estudo de viabilidade é o estudo realizado para avaliar se o projeto é viável, considerando os custos, os riscos e a projeção de retorno financeiro. Para isso é feito uma análise de oferta da região escolhida, das leis urbanísticas, é feito uma pesquisa de mercado onde são definidas as expectativas de mercado e é realizado uma análise da contabilidade e despesas como materiais, compra do terreno, taxas e tributações impostas. A partir desses estudos é feito o fluxo de caixa onde é analisado todos os custos e despesas para se obter o retorno real do empreendimento.

Outro aspecto que é realizado no pré-construção são os projetos detalhados de cada etapa da construção. O projeto principal de uma construção é o Projeto Arquitetônico, nele é definido o formato da construção, como a quantidade de andares, posição e utilidade dos cômodos entre outras coisas. Em seguida é feito o projeto legal onde é solicitada a autorização aos órgãos competentes um alvará para o início da construção. Com esses dois projetos é feito o projeto estrutural o qual define as dimensões, posições e materiais das vigas e pilares, sempre respeitando o Projeto Arquitetônico, e compatibilizando os elementos estruturais com o projeto de arquitetura. A partir disso é feito o Projeto de Fundações, onde é analisado o solo em que a construção está sendo realizada e as cargas que os elementos estruturais estão exercendo e assim é escolhida a fundação que será utilizada na construção. 


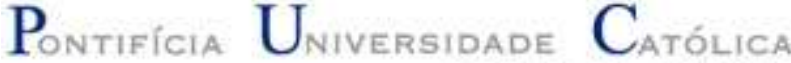 \\ DO RIO DE JANEIRO}

Na sequência, é modelado o Projeto de Instalações, onde são avaliados todos os sistemas de hidráulica, elétrica e esgoto, definidos no Projeto Arquitetônico. E são estudados os demais componentes do produto, com vistas ao atingimento de todas as demandas do cliente.

Com esses estudos realizados em conjunto, é imprescindível que os projetistas, consultores, construtora, fornecedores e clientes estejam conectados para realizar um trabalho colaborativo e possam avaliar os riscos e alternativas para possíveis problemas, seja de compatibilidade de projetos ou de mudanças ao desejo do requerimento do cliente.

Essas reuniões são de suma importância na fase de pré-construção quando é observado um problema, a resolução do mesmo acarretará custos e gastos de tempo menores.

A imagem a seguir, Figura 2.1.1.1, em verde, mostra que quanto mais próximo da data de início da construção, maior é a influência nos gastos e qualidade dos recursos. Além disso, em vermelho, é possível analisar o custo de uma mudança do projeto, onde no início a mudança se baseia simplesmente em apagar ou acrescentar uma linha no projeto, porém uma mudança com a construção já iniciada gera um custo muito maior, pois muitas vezes é necessário destruir um serviço já realizado, causando um retrabalho, um desperdício de material e um novo custo com material. 


\section{Pontifícia Universidade Catálica

Figura 2.1.1.1. - Custos ao longo da construção

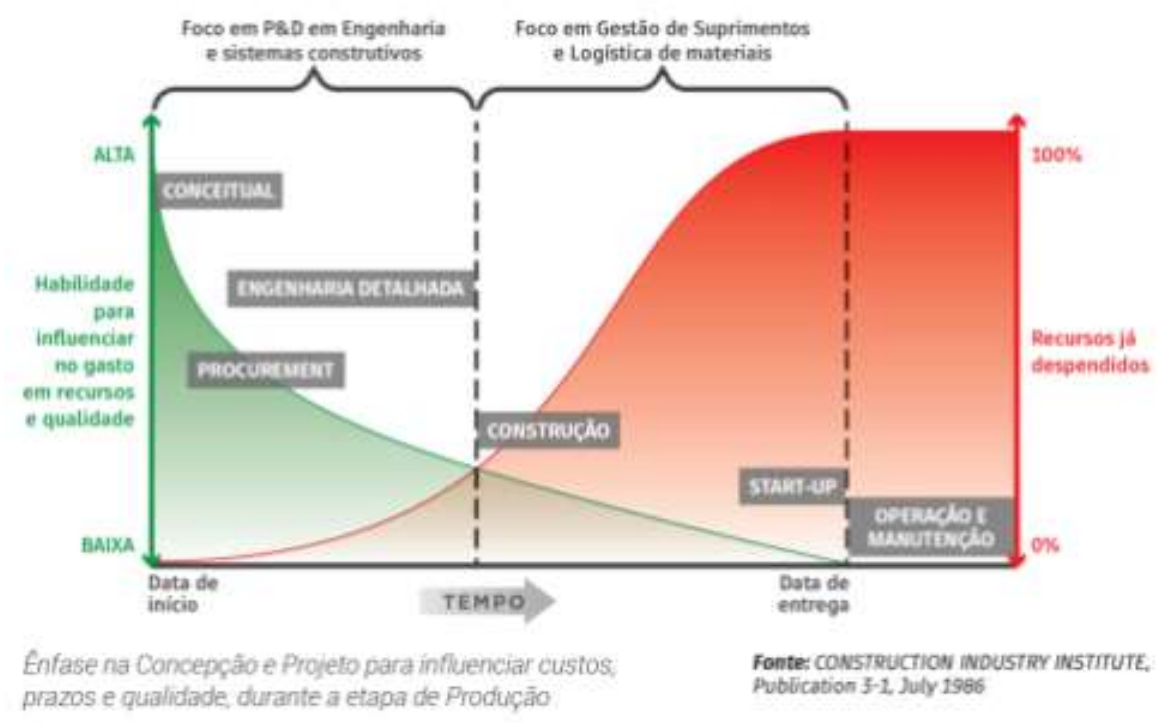

Fonte: Construction Industry Institute (1986, Publication 3-1)

Levando em conta a relevância de se realizar uma pré-construção bem elaborada para a redução de custos e de tempo, é importante utilizar a tecnologia e metodologia mais eficiente. Devido a isso será analisado o beneficio de se utilizar a metodologia BIM e os seus softwares.

\subsection{Modelagem}

A modelagem é a primeira etapa da metodologia BIM, ela consiste em transformar os projetos 2D de um certo empreendimento em um modelo 3D do mesmo, podendo ter vários projetos no mesmo modelo. Esse arquivo então é usado para a visualização do projeto final.

Está etapa permite a adoção de soluções construtivas e a avaliação em conjunto da compatibilidade das soluções arquitetônicas, estruturais e de instalações, realizando a compatibilização e correções de eventuais interferências entre todos os projetos. 


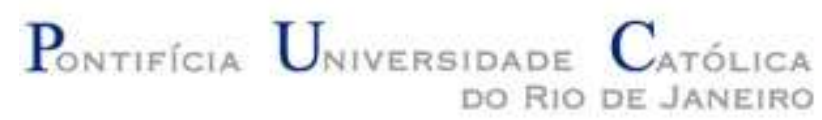

Realizada a primeira etapa de modelagem, torna-se possível a extração de dados quantitativos dos elementos da modelagem, como quantidades de materiais, por exemplo, concreto, alvenaria, formas, revestimentos, pavimentações, entre outros componentes.

Com base nesses quantitativos e índices de produtividade associados, é realizado o cálculo de dimensionamentos e prazos necessários à montagem dos cronogramas, com uso, por exemplo, do programa MS Project, da Microsoft.

A modelagem $3 \mathrm{D}$ tem diversas vantagens em relação a modelagem $2 \mathrm{D}$, que é a mais usada até os dias atuais. Primeiramente com o modelo final, é possível ver a compatibilização de diferentes projetos inseridos no mesmo. Dentro do software Revit, por exemplo, tem um comando que analisa as incompatibilidades de projetos, para que o responsável possa adaptar o modelo antes mesmo da construção. Um dos maiores problemas na construção, hoje em dia, é a falta de troca de informações de um projeto com o outro, por exemplo, a planta de elétrica de um apartamento pode ter conflitos com a planta de estruturas, e o engenheiro só vê essas incompatibilidades no momento da construção.

Outra importante vantagem, é o fato do aplicativo com metodologia BIM poder além de implementar a modelagem paramétrica dos sólidos, implementar, também, a modelagem não paramétrica. Esse quesito permite que as linhas e sólidos carreguem mais informações, como por exemplo, de quais materiais vão ser, as espessuras, os pesos, resistências, etc. Esse fato facilita as próximas fases da metodologia BIM. 


\subsubsection{Software}

Além de ambos os tópicos mencionados acima, os softwares usados permitem uma visualização antes considerada complicada, como a realização de cortes em qualquer setor da estrutura, com apenas um clique, qualquer pessoa pode ver qualquer detalhe do empreendimento. Além do corte, é possível realizar, também, passeios virtuais ao longo do projeto, possibilitando a visualização interna do mesmo, facilitando as escolhas que devem ser realizadas pelo cliente.

\subsubsection{AutoDesk}

A Autodesk é uma das principais plataformas de softwares com metodologia BIM existentes no mercado. Através dessa plataforma, tem-se acesso a diversos Softwares que integram tal metodologia e se conversam entre si. Para o planejamento $3 \mathrm{D}$, o principal Software da plataforma é o Revit. Para as próximas etapas, 4D, cronograma, e 5D, orçamento, a Autodesk conta com o aplicativo Navisworks, que irá utilizar os dados do Revit para gerar o cronograma e o orçamento da construção

\subsubsection{Revit}

O Revit é um dos principais aplicativos de BIM para modelagem, sendo usado pela maioria dos engenheiros que estão envoltos nesse mercado. Ele apresenta dois grandes benefícios aos softwares utilizados fora da metodologia BIM, a modelagem 3D e o detalhamento dos elementos projetados.

A modelagem volumétrica dos elementos traz vantagens tanto para a visualização de problemas de sobreposição, como para um melhor entendimento da execução empreendimento e a visualização do projeto final em 3D. O programa sinaliza facilmente a sobreposição dos elementos, pois nele é possível realizar todos os projetos no mesmo modelo. Logo, caso duas tubulações estejam se cruzando, o programa indica a existência 


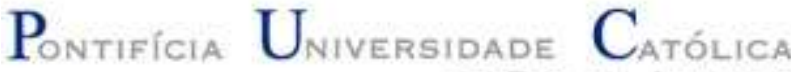

de um erro. Além disso, a visualização da construção também é aprimorada, pois no aplicativo é possível entrar na construção e observar o interior, o que facilita o entendimento de como o empreendimento deve ficar. Ademais, é possível conectar um óculo de realidade virtual e assim o cliente pode entrar e passar pelo empreendimento que está comprando.

O outro grande benefício do Revit é o detalhamento dos elementos, com isso o programa entende o que está sendo projetado. Para o detalhamento é necessário ter ou criar um template onde existam alguns detalhes dos elementos que serão utilizados. Assim, por exemplo, quando for ser desenhada uma parede, é necessário escolher o tipo de parede que será utilizado e o programa já ira mostrar a parede com as dimensões escolhidas e as características dos materiais escolhidos, como mostra a Figura 2.2.3.1.

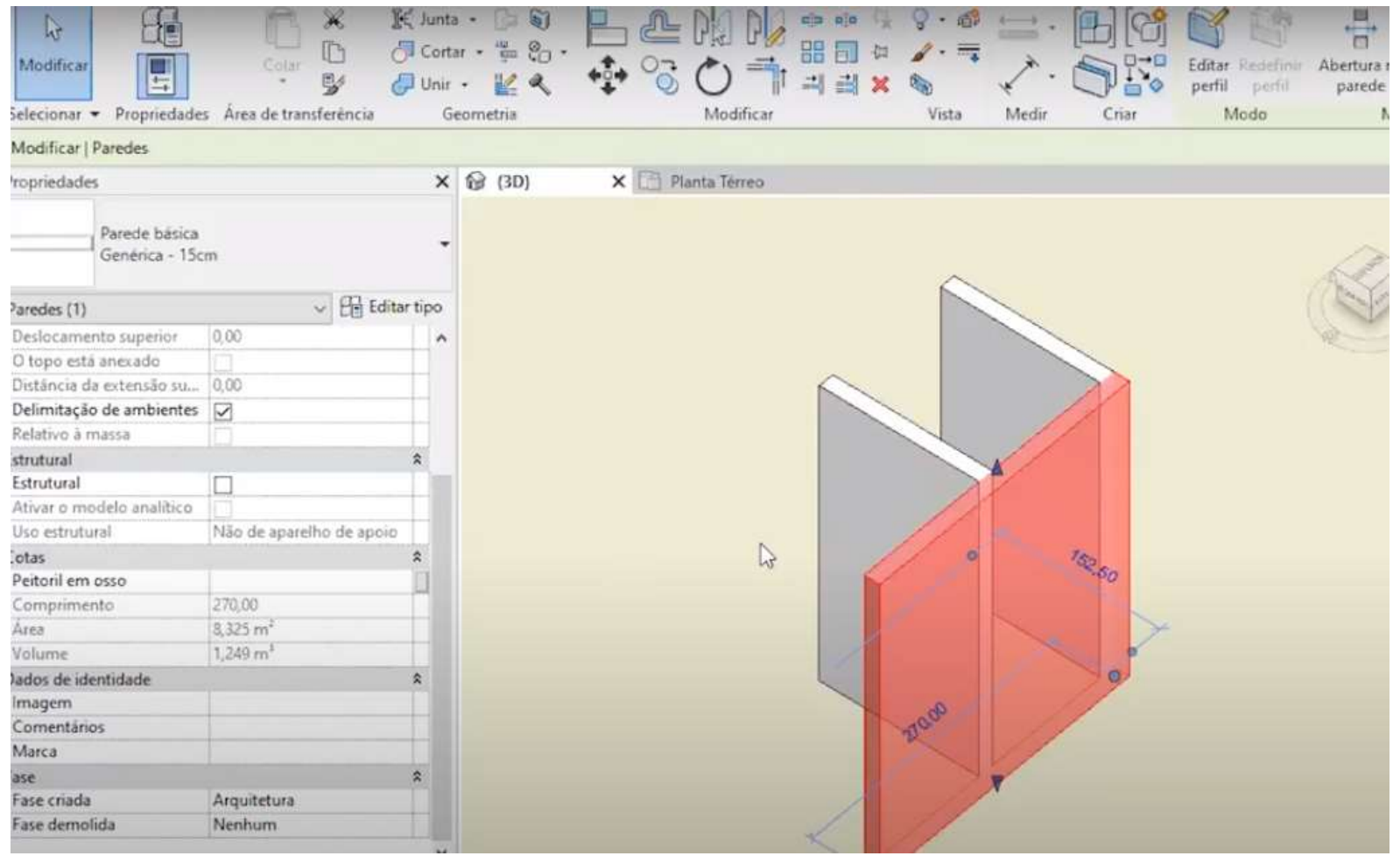

Figura2.2.3.1 - Desenho de parede do Revit

Nessa figura é possível observar que com um simples desenho de uma linha, o Revit já faz o desenho de uma parede com altura, espessura e materiais pré-determinados e fornece a comprimento, a área e o volume desse elemento. Todas essas informações 


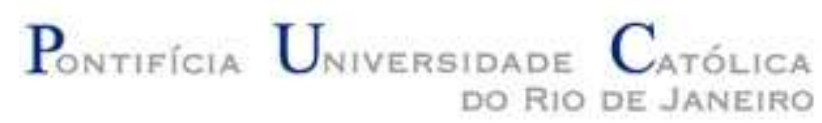

causam uma demora um pouco maior na hora de desenhar um projeto, porém quando a construção é toda feita dessa forma, ao final da modelagem é possível obter quais materiais e a quantidade de cada um deles que será necessária ao longo da construção. Essa ferramenta gera uma eficiência nas próximas etapas do planejamento, como o cronograma e orçamento.

\subsection{Cronograma}

O cronograma faz parte do Planejamento 4D dentro da metodologia BIM, que consiste em somar à modelagem 3D ao fator tempo, organizando a execução dos serviços em ordem cronológica. A partir dessa união é possível acompanhar o desenvolvimento da construção com o modelo 3D dos serviços que já foram e serão realizados.

O Planejamento 4D é feito pelo vínculo dos objetos realizados na modelagem com uma atividade do cronograma. Isso é feito, por exemplo, definindo que os pilares do primeiro pavimento serão os primeiros a serem realizados. Dessa forma é possível visualizar em uma animação a realização dos serviços periodicamente.

Um dos maiores benefícios em realizar essa animação é poder pausar, retroceder e avançar a qualquer momento, facilitando o entendimento de como e onde serão realizados os próximos serviços. Além disso, é possível observar qualquer ponto da modelagem sendo dentro ou foram da edificação.

Outra possibilidade com a metodologia BIM é poder acrescentar equipamentos provisórios de construção como gruas. Com essa ferramenta a análise desses equipamentos no cronograma fica preciso, pois ele permite visualizar a utilidade dele em cada serviço. 


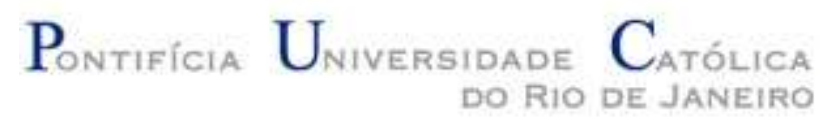

Além do mencionado anteriormente, a visualização 3D de cada etapa dos serviços facilita a observação de possíveis erros realizados na execução dos serviços, os quais poderiam gerar uma maior perda de tempo de dinheiro caso vistos posteriormente. Esta visualização também permite gerar diversas simulações com ordem cronológicas das atividades diferentes, facilitando o estudo de qual ordem utilizar.

\subsubsection{MS Project}

O MS Project é um software que realiza um planejamento de sequencia de trabalhos. O programa foi desenvolvido para organizar serviços de qualquer natureza, porém, devido à construção civil ser constituído de uma sequência de atividades, o software passou a ser muito utilizado nas construções de todo o mundo.

Um grande benefício do MS Project é a possibilidade de fazer um fácil comparativo do cronograma previsto inicialmente e a situação da construção naquele instante. Com esse comparativo são feitas análises que proporcionam maior entendimento da construção e assim facilita a tomada de decisão e realização um melhor gerenciamento da construção.

A realização de um cronograma no Project é feito a partir de uma sequência de serviços. Para isso, são colocadas de forma cronológica todas as atividades que serão realizadas. Após, é definido o tempo de duração de cada serviço e inseridas as predecessoras de cada atividade. Dessa forma, fica entendido que um serviço só pode começar após o termino do serviço anterior, como pode ser visto na Figura 2.3.1.1, o inicio da execução do pilar do $2^{\circ}$ Tipo só pode iniciar após o pilar do $1^{\mathrm{o}}$ Tipo estar finalizado. 


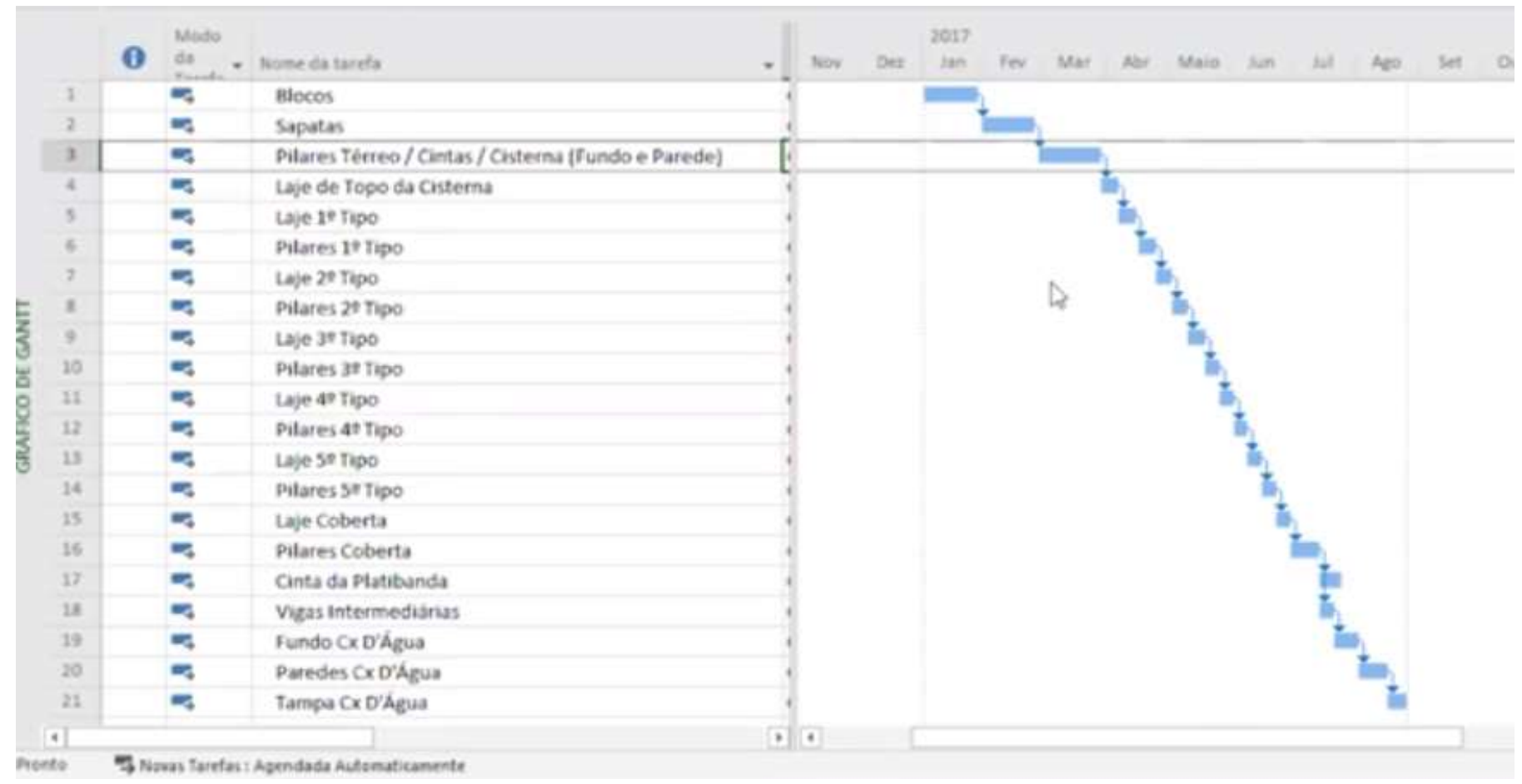

Figura 2.3.1.1 - Cronograma MS Project

Com essa estrutura realizada é possível obter uma serie de analises, como por exemplo, a linha critica, onde o programa indica os serviços que tem uma maior influencia sobre a cronologia da construção, pois são os serviços predecessores dos outros onde o atraso de algum deles pode gerar um atraso da construção toda. Outro beneficio do software é que ele analisa a influencia da quantidade de pessoas trabalhando em uma atividade, assim é possível observar a mudança do cronograma ao acrescentar ou retirar funcionários de um serviço específico.

O programa traz uma grande quantidade de benefícios, porém dentro da metodologia BIM ele fica ainda mais completo. A compatibilidade com outros softwares pode indicar problemas que o MS Project não analisa por falta de informação de outros setores. 


\section{Pontifícia U Uiversidade Catálica $_{\text {a }}$}

\subsubsection{Navisworks}

O Navisworks é um dos softwares que melhor representa a metodologia BIM, pois a função dele é compatibilizar os projetos de diversos setores diferentes em um só modelo. Dentro do planejamento 4D, o Navisworks funciona como um compatibilizador entre a modelagem 3D e um programa que faz a gestão da construção no tempo, como por exemplo, o MS Project, gerando uma animação que mostra o modelo 3D na linha do tempo.

Para o funcionamento do Navisworks é necessário que a modelagem $3 \mathrm{D}$ e o cronograma já tenham sido feitos. A partir disso, as informações dos dois programas são inseridos no Navisworks, com isso é visualizado a modelagem importada em 3D com as nomenclaturas e definições já determinadas do software anterior e um cronograma importado. Nesse momento é necessário linkar as nomenclaturas feitas na modelagem com as do cronograma, para que o software entenda onde cada elemento da modelagem está presente no cronograma, como mostra a Figura 2.3.2.1.

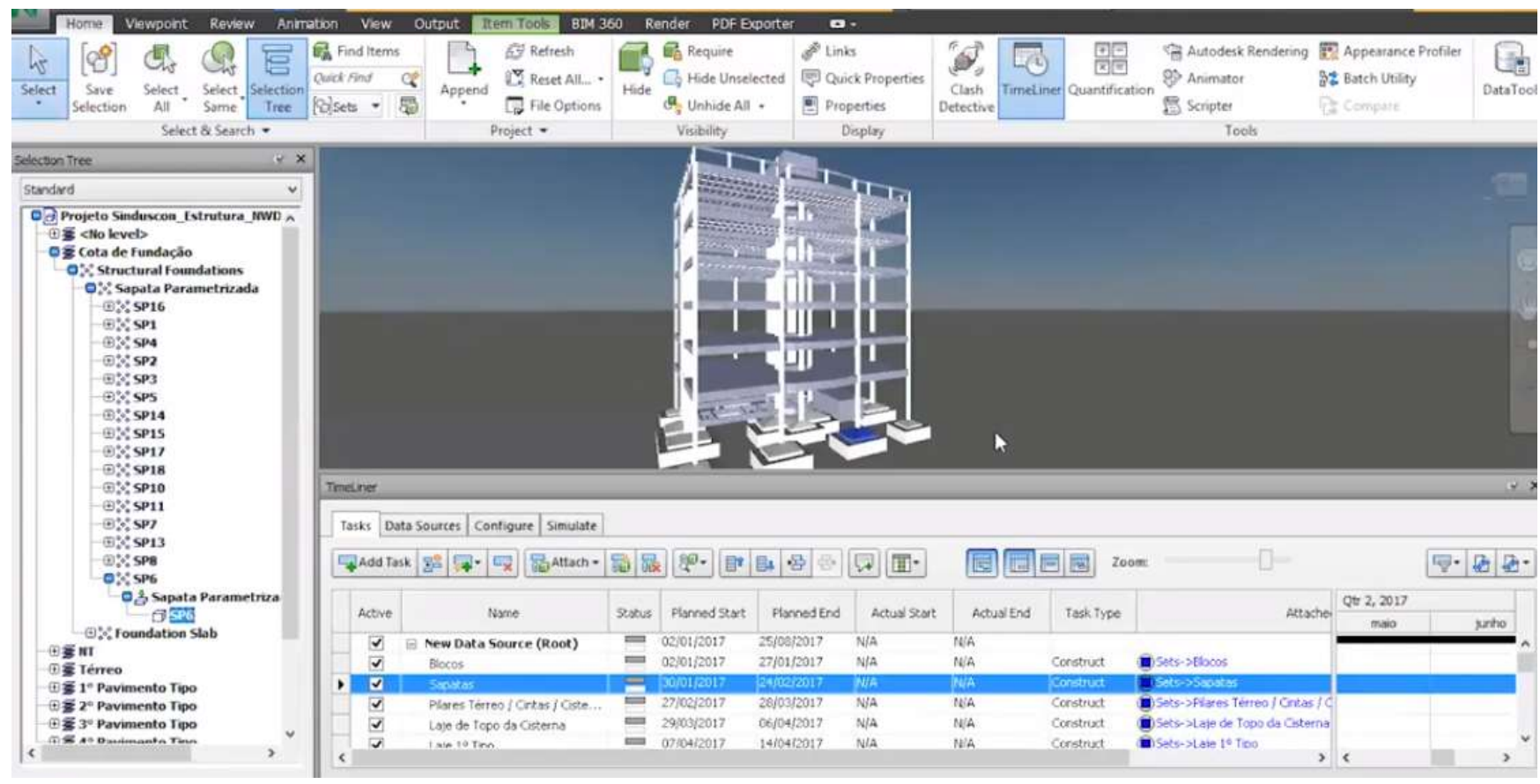

Figura 2.3.2.1 - Compatibilização Navisworks 


\section{Pontifícia Universidade Chtólica DO RIO DE JANEIRO}

Com todos os elementos ligados é possível realizar uma animação com o processo executivo de toda a construção. Essa animação pode ser pausada, avançada e retrocedida o quanto desejar, facilitando a visualização de um possível problema. Devido à completa modelagem 3D, é possível também analisar o avanço da construção pelo interior da modelagem. Essa visualização facilita a percepção de algum problema de projeto, como a execução das vigas da caixa d'agua antes da finalização dos pavimentos abaixo, como mostra a Figura 2.3.2.2.

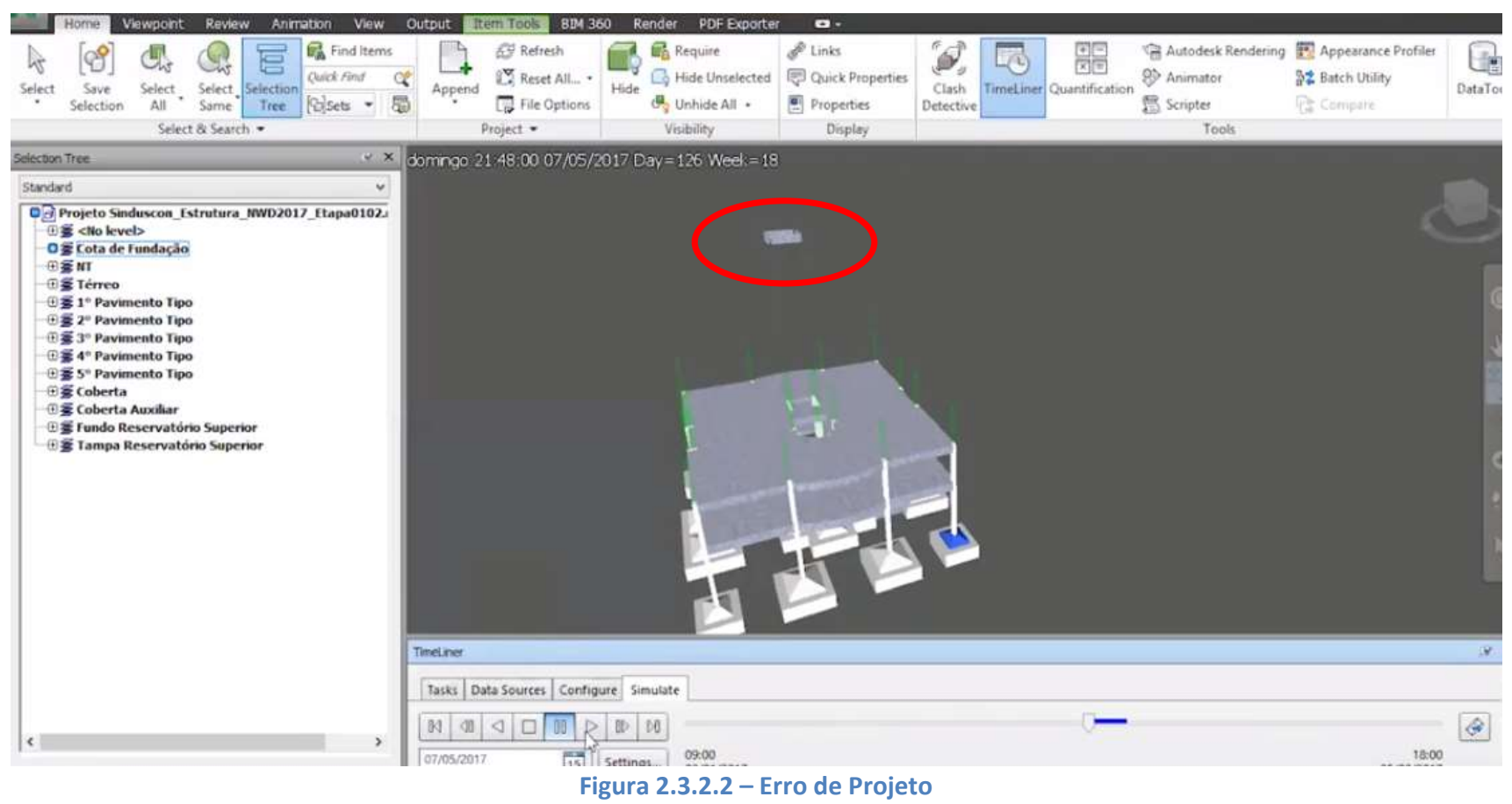

O erro mostrado acima ocorreu pelo posicionamento equívoco da execução das vigas da caixa d'agua na modelagem 3D e só foi possível de ser resolvido devido a visualização da modelagem 3D com o cronograma. Esse erro sozinho não geraria uma perda significativa de tempo e dinheiro, porém pequenos erros em vários diferentes projetos geram uma grande confusão na execução da construção. 


\subsection{Orçamento}

Primeiramente, o orçamento é uma das partes mais relevantes para o cliente. Essa etapa é a qual decide se o projeto vai estar dentro do programado ou se será necessária alterações no mesmo, ocasionando assim modificações na modelagem e até mesmo no cronograma. É importante ressaltar, que os "Ds" da metodologia BIM, não são necessariamente dependentes um do outro. Dito isso, não é necessário haver um cronograma para que se gere um orçamento, no entanto, o orçamento estaria bastante defasado caso não ocorra o " $\mathrm{D}$ " anterior. Outro importante fator a ser considerado é que o orçamento nunca será idêntico às despesas reais. Ele serve apenas como uma estimativa do que será gasto, já que simula uma produtividade de mão de obra de construção baseada em um fator, que não é a produtividade que ocorre na realidade.

A metodologia BIM, assim como as outras partes do planejamento, ajuda bastante nessa etapa, apesar de não ter um software específico para isso. No entanto, através dos programas usados para modelagem, é possível facilitar o processo, além de deixá-lo mais preciso.

O processo implica em além de adicionar as informações referentes a parametrização dos objetos, inserir também informações referente a preço unitário do mesmo. A partir disso, o software, poderá calcular os valores somados finais de todos os itens. 


\section{Pontifícia Universidade Catálica $_{\text {a }}$}

\subsubsection{REVIT + Excel}

Uma das formas de ser realizado o orçamento 5D, é através da junção do REVIT com o Excel. A partir da modelagem com as informações completas dos materiais que estão usando, como mostrado na Figura 2.4.1.1, é possível extrair uma tabela Excel do software de modelagem e a partir dessa tabela, acrescentar os cálculos de taxa de administração, e outros valores que se julgarem necessários.

Um importante fator nessa forma de realizar, é que como é necessário o uso do humano para o cálculo final, pode-se ocorrer erros nessa etapa. Também é relevante ressaltar que toda e qualquer mudança realizada no REVIT, será necessário atualizar manualmente a planilha Excel, tendo sempre que extrair uma planilha de custos nova. Além disso, esse orçamento não contará com custos relacionados à cronograma, como custo de mão de construção, aluguel de equipamentos materiais, etc.

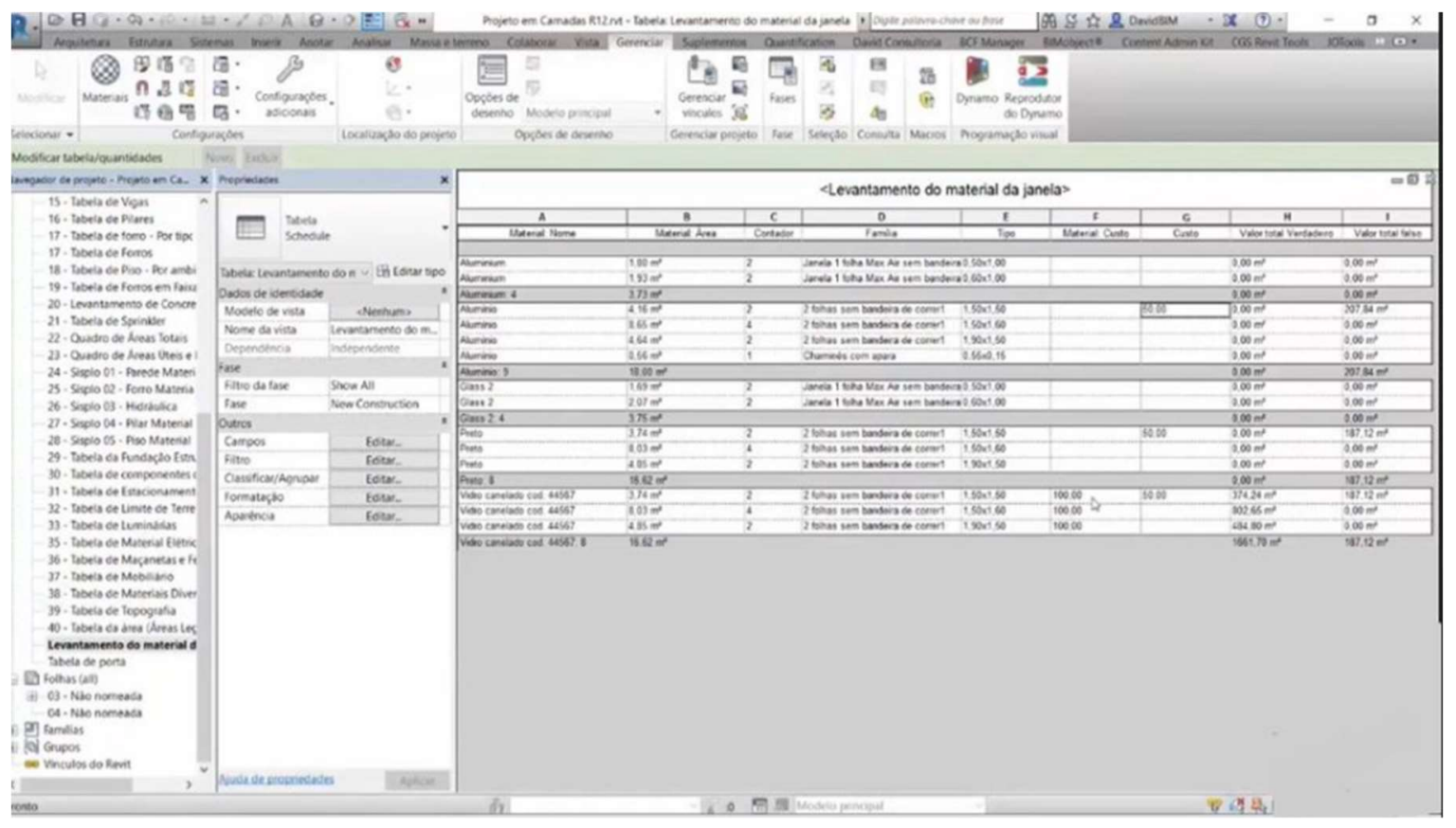

Figura 2.4.1.1 - Orçamento Revit 


\section{Pontifícia U Uiversidade Cátólica $_{\text {a }}$}

\subsubsection{Navisworks}

Como foi analisado anteriormente para o cronograma, o Software Navisworks tem como última etapa, a formação do orçamento completo, Figura 2.4.2.1, com todas as informações das duas fases anteriores. O programa resultará em um orçamento detalhado com medições e custos, possibilitando também, a extração da curva $A B C$ do empreendimento.

Dentro do Navisworks, é possível acrescentar ao item, a sua composição analítica, que está no canto inferior esquerdo da Figura 2.4.2.1, e a partir dessa composição, o programa já calcula, através de uma fórmula informada, a quantidade total de cada item. O usuário, então, acrescenta o valor unitário, resultando, assim, no cálculo total.

Um dos pontos mais positivos desse método, é que qualquer alteração realizada no projeto ou cronograma, é contabilizada automaticamente no orçamento final, já que todas as fases estão integradas nesse aplicativo.

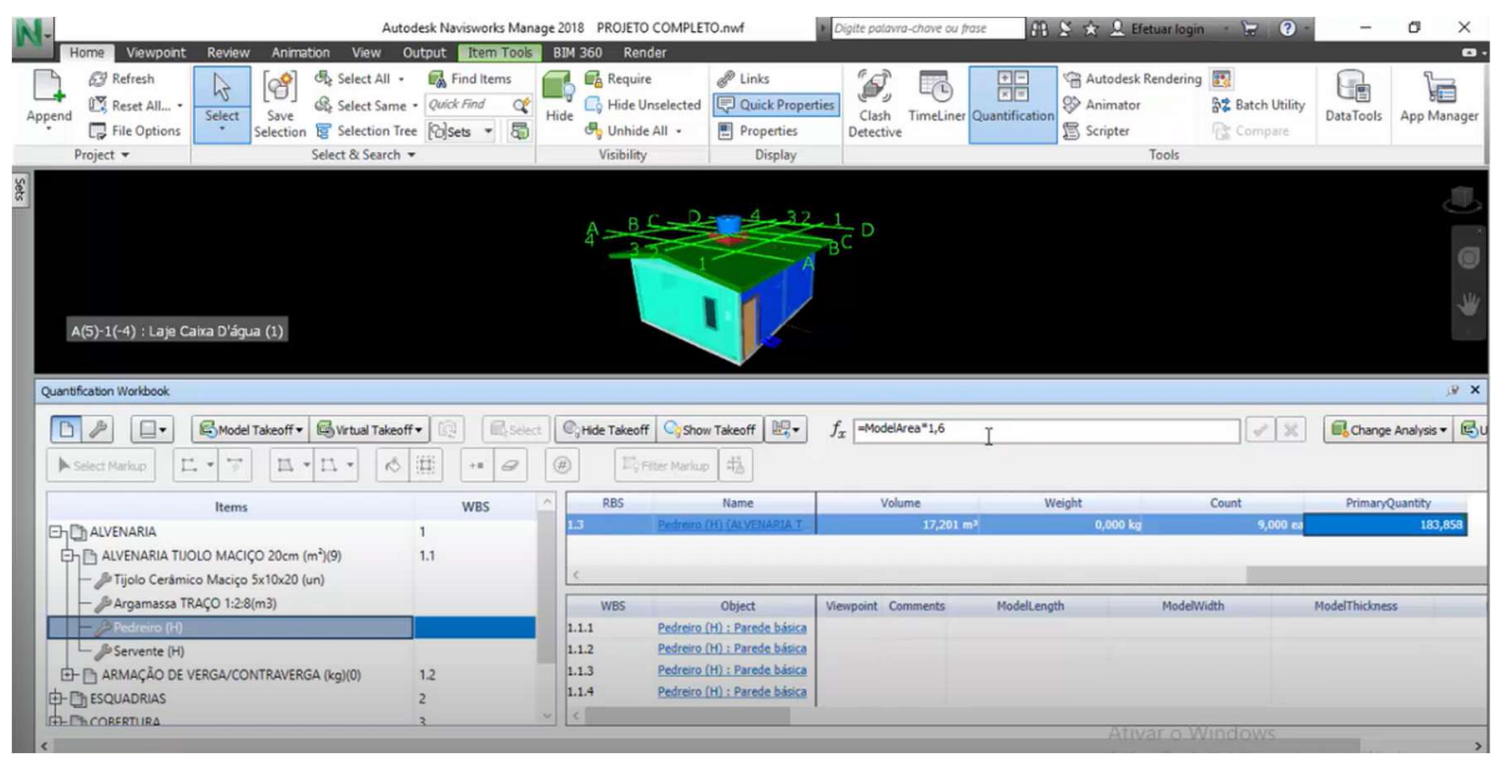

Figura 2.4.2.1 - Orçamento no Navisworks 


\section{BIM NO MUNDO}

A metodologia BIM é uma ferramenta da indústria da construção civil que afeta tanto questões políticas, quanto econômicas nacionais e internacionais. Essa grande influencia se deve pelo fato de o BIM ter como objetivo uma diminuição significativa do custo e do tempo de todas as construções. Assim, com custos reduzidos, os governos podem investir mais em construções de infraestrutura. Todo esse investimento pode gerar um aumento no PIB do país. Devido a isso, diversos países no mundo têm incentivado a utilização da metodologia BIM. Aqui será analisado o desenvolvimento do BIM em 5 países: Estados Unidos, Reino Unido, França, China e Brasil.

\subsection{Estados Unidos}

Os Estuados Unidos foi o país responsável pela criação da metodologia BIM nos anos 70, porém somente nos anos 2000 que o mercado norte americano viu essa metodologia como algo viável na construção civil (referenciar). A partir desse momento o país foi se desenvolvendo, porém de uma maneira bem mais lenta do que se é esperado. Isso se deve a grande burocracia e a falta de padronização entre os estados, tornando a metodologia nos EUA baseado no sistema Cliente individual/Contratado.

Em 2006 o governo norte americano tornou obrigatória a utilização da metodologia em todos os projetos federais. Alguns anos depois foi criada o National Institute of Building Science (NIBS) que é uma organização que tem como objetivo identificar e resolver problemas potenciais que dificultam a disseminação do BIM nos EUA. Eles desenvolveram um documento que mostrou que o BIM reduz em 5\% os custos finais de construção, aumenta em $5 \%$ a velocidade de construção e reduz em $25 \%$ a mão de 


\section{Pontifícia Universidade Catálica

construção empregada. Esse documento deixou evidente o aumento do retorno do investimento do uso de BIM, fazendo a metodologia BIM algo indispensável para a inovação nos processos de construção.

\subsection{Reino Unido}

O Reino Unido, atualmente, é o país mais desenvolvido na questão do BIM. Em 2011, o governo britânico criou a Estratégia de Construção do Governo do Reino Unido que tem como objetivo a disseminação da plataforma nos empreendimentos públicos e privados. Essa estratégia visa diminuir em $20 \%$ o custo dos projetos de construção. Para isso foi implementado a Estratégia de Pousos Suaves do governo (GSL) seguindo o modelo Bew-Richards de nível de maturidade, como mostra a Figura 3.2.1 abaixo.

Figura 3.2.1 - Modelo Bew-Richards

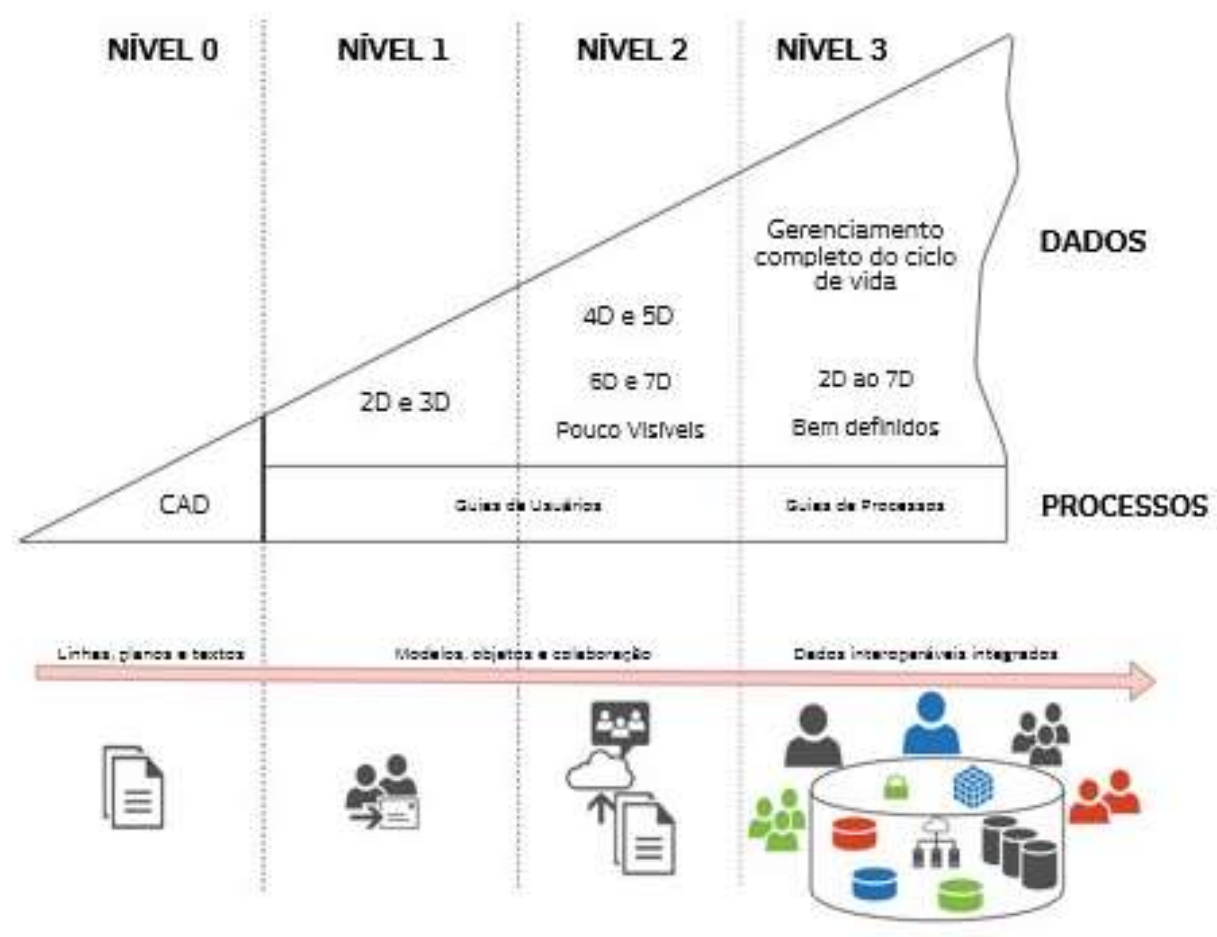

Fonte: BIM Industry Working Group (2011) 


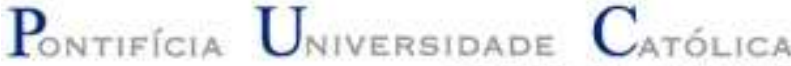 \\ DO RIO DE JANEIRO}

O Reino Unido está nesse momento no Nível 2 tentando avançar para o Nível 3. Devido a isso, eles tem como objetivo até 2025 reduzir os gastos iniciais com edificações e manutenções em 33\%, reduzir gases de efeito estufa em 50\% e reduzir o tempo médio de projeto e construção em 50\%.

\subsection{França}

A França é outro país que tem se desenvolvido bastante nos últimos anos na metodologia BIM, uma pesquisa em 2010 mostrou que $40 \%$ dos arquitetos, $29 \%$ das empreiteiras e 44\% dos engenheiros já usavam o BIM. Em 2015, eles criaram um plano para disseminar gradativamente o BIM e aos poucos tornar a metodologia obrigatória nas licitações públicas. Para esse desenvolvimento gradativo o governo francês criou a plataforma pública KROQI, a logo da plataforma está presente na Figura 3.3.1.

Figura 3.3.1 - Logo da KROQI

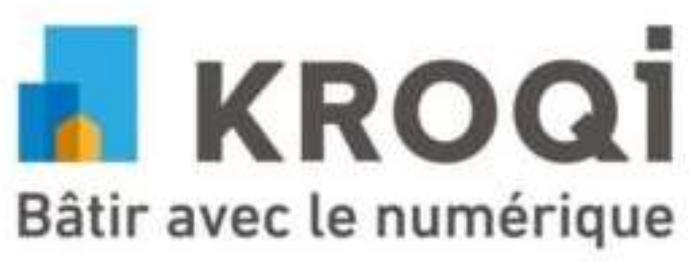

Fonte: kroqui.fr

A ideia dessa plataforma é incentivar as empresas pequenas a utilizar a metodologia BIM, para isso eles disponibilizaram de forma gratuita diversos softwares que são utilizados no BIM. Graça a essa plataforma, a França pretende atingir um alto nível de implementação até 2022 . 


\subsection{China}

A China tem crescido de forma exponencial, principalmente desde 2016, tendo um crescimento na quantidade de arquitetos que utilizam a metodologia de $89 \%$ e de $108 \%$ para os engenheiros. O governo chinês tem se inspirado nas experiências de sucesso dos modelos do Reino Unido e dos Estados Unidos, porém ainda não tornaram obrigatória a utilização da metodologia nas construções públicas.

A China utilizou esse método em 3 gigantes construções civis: Shangai Tower, Phoenix Media Center e Xangai Disneyland Resort. Utilizando a metodologia BIM, a Shangai Tower, um edifício de 632 metros, foi construída em 73 meses, 30\% mais rápido que as construções de edifícios semelhantes. No Phoenix Media Center, com $65.000 \mathrm{~m}^{2}$, a metodologia ajudou a reduzir dificuldades de projeto, economia de tempo e aumento da qualidade. Além disso, foi feito um modelo digital que permite planejar e gerenciar o edifício. O Xangai Disneyland Resort foi uma construção com diversos edifícios, onde $70 \%$ deles foi feito com a metodologia BIM. O uso desta metodologia, não só ajudou a ter um controle das construções que estavam funcionando simultaneamente, como também auxiliou a comunicação entre o Walt Disney Imagineering e as construtoras e escritórios de arquitetura locais.

\subsection{Brasil}

No Brasil, diferente dos outros países, a metodologia ainda é vista como uma novidade e poucas pessoas efetivamente a utilizam, mas a procura pelo desenvolvimento tem aumentado nos últimos anos. O governo brasileiro tentando incentivar o crescimento da metodologia estabeleceu dois decretos, um em 2019 e o segundo em 2020. 


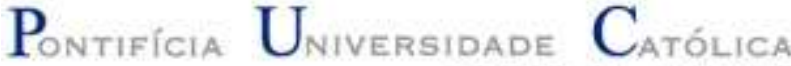 \\ DO RIO DE JANEIRO}

O primeiro decreto, decreto $n^{\circ} 9.983$, tem como objetivo estimular a implementação do BIM de forma gradativa, baseado na Estratégia de Pouso Suaves (GSL) do Reino Unido. Para isso, foi estipulado o desenvolvimento da Plataforma e Biblioteca Nacional BIM, a produção de normas técnicas, guias e protocolos específicos, a criação de condições favoráveis para o investimento público e privado, estimulando a concorrência, assim como a criação do comitê de gestor da estratégia, entre outros.

No decreto de 2020, decreto $\mathrm{n}^{\circ} 10.306$, estabelece o início da fase 1 da implementação do BIM, onde a partir de 2021 todos os projetos públicos de pré-construção devem obrigatoriamente utilizar a metodologia BIM. Em 2024, iniciará a fase 2 onde o cronograma e o orçamento também deverão utilizar a metodologia. Por último em 2028, iniciará a fase 3 que obriga a utilização da metodologia na sustentabilidade e na manutenção das construções. Com esse planejamento, o governo brasileiro, pretende que $50 \%$ do PIB da construção civil utilize a metodologia BIM.

\section{CONCLUSÃO}

É uma certeza que na construção civil, ao longo do projeto, ocorram contratempos das mais diversas formas. A metodologia BIM surge, justamente, para diminui-las ao máximo, salvando assim, tempo e investimento necessário.

Pode-se afirmar que durante a fase de modelagem do empreendimento, a modelagem 3D fornece diversos benefícios em relação a modelagem $2 \mathrm{D}$, que os engenheiros estão mais acostumados. Sendo eles, a visualização da construção de forma tridimensional, além da compatibilização de todos os projetos para que não haja interferências entre eles. 


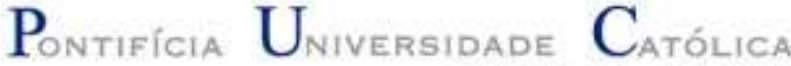 \\ DO RIO DE JANEIRO}

Por todas as etapas dos planejamentos estarem ligadas através das plataformas que possuem a metodologia BIM, as etapas de cronograma e orçamento, são realizadas de forma mais precisa e direta, facilitando a análise de inconsistências e conflitos no projeto.

Além disso, cada etapa possui benefícios em relação à forma em que são feitas nos dias atuais, justamente por obterem informações importantes desde a fase da modelagem da construção, permitindo, assim, que quaisquer alterações realizadas desde a primeira fase da metodologia BIM, seja trazida até a fase que está sendo realizada.

No Brasil, a implementação da metodologia BIM ainda está em fase inicial. O governo brasileiro tem feito decretos para incentivar o uso dessa metodologia, obrigando a utilização da mesma nos projetos das construções públicas, porém o Brasil tem muita resistência à mudança, devido ao alto valor dos softwares e da falta de mão de obra especializada. Apesar disso a metodologia já é conhecida pela grande maioria dos profissionais da área, que procuram cada vez mais implementar a metodologia.

A realização desse trabalho foi interessante, de forma que, por ser um tópico relativamente novo no Brasil, não possui diversas literaturas e opiniões sobre. Por isso, necessitou que os autores fossem buscar dados do uso de cada Software mencionado, o

que se tornou bastante didático. Se tornando uma pesquisa de bastante interesse e importância, os autores, vendo todos os benefícios e vantagens que o BIM fornece à construção, foram incentivados a tentar aplicar tal metodologia em seus próprios locais de trabalho. 


\section{REFERÊNCIAS BIBLIOGRÁFICAS}

LIMMER, CARL VICENTE. Planejamento, Orçamentação e Controle de Porjetos e Construções. $1^{a}$ Edição. Local de publicação: LTC, 26 de novembro de 1996.

CHIAVENATO, IDALBERTO. Introdução à Teoria Geral da Administração. $7^{\mathrm{a}}$ Edição. Local de publicação: Elsevier Editora Ltda, 2003.

DARÓS, José. União do BIM 3D, 4D e 5D na prática. Utilizando BIM, 06 de novembro de 2019. Disponível em: https://utilizandobim.com/blog/uniao-bim-3d-4d-5d/. Acesso em: 14 de outubro de 2021.

O que é pré-construção e quais seus benefícios. Sienge. Disponível em: https://www.sienge.com.br/blog/pre-construcao-paulo-oliveira/. Acesso em: $18 \mathrm{de}$ outubro de 2021.

Estudo de viabilidade técnica da construção: como ele é feito?. IBEC, 13 de janeiro de 2021. Disponível em: https://ibecensino.org.br/blog/viabilidade-tecnica/. Acesso em: 18 de outubro de 2021.

Construção de Casa: Saiba quais são os Projetos que você vai precisar. AWL Engenharia, 27 de julho de 2020. Disponível em: https://www.awlengenharia.com/post/construcaode-casa-saiba-quais-sao-os-projetos-que-voce-vai-precisar. Acesso em: 18 de outubro de 2021.

Entenda o que é AutoCad e qual a sua importância!. Razor Computadores, 28 de abril de 2020. Disponível em: https://razorcomputadores.com.br/blog/tecnologia/o-que-eautocad/. Acesso em: 23 de outubro de 2021.

BIM 5D, a quinta dimensão do BIM. BibLus, 4 de junho de 2019. Disponível em: https://biblus.accasoftware.com/ptb/bim-5d-a-quinta-dimensao-do-bim/. Acesso em: 29 de outubro de 2021.

5 formas de utilizar o 3D do BIM. Escola de BIM, 2018. Disponível em: https://www.youtube.com/watch?v=0JKWnfUpNVQ. Acesso em: 24 de outubro de 2021.

Planejamento 4D. Escola de BIM, 2018. Disponível em: https://www.youtube.com/watch?v=EkP5gVE997o. Acesso em: 24 de outubro de 2021.

4 formas de fazer um Orçamento 5D. Escola de BIM, 2018. Disponível em: https://www.youtube.com/watch?v=CaO-3hsWn54. Acesso em: 24 de outubro de 2021. 


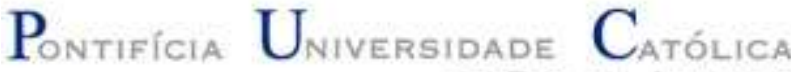 \\ DO RIO DE JANEIRO}

Planejamento no MS Project Integrado ao BIM. InovaCivil, 5 de agosto de 2019. Disponível em: https://www.youtube.com/watch?v=e6rZEN4bbsc. Acesso em: 1 de novembro de 2021.

A Integração do Ciclo BIM com Navisworks. InovaCivil, 17 de outubro de 2019. Disponível em: https://www.youtube.com/watch?v=dKXmUsnfAeI. Acesso em: 1 de novembro de 2021.

RIBEIRO, Clara. Navisworks: saiba tudo sobre o uso do software na Engenharia. Engenharia 360, 06 de novembro de 2020. Disponível em: https://engenharia360.com/Navisworks-saiba-tudo-sobre-o-uso-do-software-naengenharia-licenca-gratuita/. Acesso em: 10 de novembro de 2021.

BIM no mundo: confira a revolução da indústria da construção. BibLus, 9 de março de 2020. Disponível em: https://biblus.accasoftware.com/ptb/bim-no-mundo-confira-arevolucao-da-industria-da-construcao/. Acesso em: 11 de novembro de 2021.

BIM no mundo: os investidores do BIM ficaram para trás. BibLus, 19 de fevereiro de 2019. Disponível em: https://biblus.accasoftware.com/ptb/bim-no-mundo-os-inventoresdo-bim-ficaram-para-tras/. Acesso em: 11 de novembro de 2021.

Implementação de BIM no Brasil e ao redor do mundo. Neo Ipsum, 07 de agosto de 2020. Disponivel em: https://neoipsum.com.br/implementacao-de-bim-no-brasil/. Acesso em: 11 de novembro de 2021.

BIM no mundo: 3 projetos realizados na China. BibLus, 9 de juho de 2019. Disponivel em: http://biblus.accasoftware.com/ptb/bim-no-mundo-3-projetos-realizados-na-china/. Acesso em: 11 de novembro de 2021.

Curso Introdução ao mundo BIM - Orçamento no Navisworks. Leiaut Carielo, 16 de abril de 2019. Disponível em: https://www.youtube.com/watch?v=H77gJI129jg. Acesso em: 11 de novembro de 2021.

O Revit sendo utilizado na prática. InovaCivil, 21 de janeiro de 2020. Diponível em: https://www.youtube.com/watch?v=rT27sdOyisk. Acesso em: 11 de novembro de 2021. 